\title{
Pengaruh Penambahan Corn Cob Ash dan Bagasse Ash terhadap Setting Time dan Kuat Tekan Material berbasis Semen
}

\author{
Andrie Harmaji ${ }^{1}$, Thea Gita Permata ${ }^{2}$, \\ Dimas Yassin Hendriyanto ${ }^{3}$, Syoni Soepriyanto ${ }^{4}$ \\ 1,2,3,4. Teknik Metalurgi, Fakultas Teknik dan Desain, Institut Teknologi dan Sains Bandung, Deltamas, Indonesia
}

\begin{abstract}
Abstrak
Indonesia merupakan negara 10 besar penghasil Jagung dan Tebu. Limbah bonggol jagung dan Ampas Tebu masih belum banyak dimanfaatkan. Corn Cob Ash (CCA) dan Bagasse Ash (BA) memiliki komposisi $\mathrm{SiO}_{2}$ dan $\mathrm{Al}_{2} \mathrm{O}_{3}$ seperti Semen Tipe I menggunakan metode XRF. Pasta dibuat dengan mencampurkan Semen, Corn Cob Ash/Bagasse Ash, dan air dengan w/c 0.6. Sampel kemudian diuji Setting Time, dan kuat tekan. Dengan substitusi 25\% semen, nilai kuat tekan semen dengan campuran CCA dan BA adalah masing-masing $8.82 \mathrm{MPa}$ dan $1.33 \mathrm{MPa}$.
\end{abstract}

Kata-kunci: Corn Cob Ash, Bagasse Ash, Setting Time

\section{PENDAHULUAN}

Semen merupakan bahan utama untuk material bangunan. The Associated Cement Companies (ACC) Limited India menyatakan bahwa kebutuhan semen akan meningkat di Tahun 2018. Selain itu, analis Bank Mandiri Romauli Panggabean menyatakan bahwa kapasitas produksi semen di Indonesia akan naik menjadi 120 juta ton per tahun pada 2021. Namun, produksi semen ini memiliki dampak negatif pada lingkungan, untuk memproduksi satu ton semen menghasilkan satu ton gas karbondioksida $\left(\mathrm{CO}_{2}\right)^{1)}{ }^{2}$. Oleh karena itu, diperlukan material untuk substitusi parsial yang memiliki komposisi mirip dengan semen. Komposisi utama yang berperan untuk menghasilkan material yang memiliki sifat mekanik yang baik pada semen adalah alumina $\left(\mathrm{Al}_{2} \mathrm{O}_{3}\right)$, silika $\left(\mathrm{SiO}_{2}\right)$, dan $\mathrm{CaO}^{3)}{ }^{4}$. Indonesia merupakan negara penghasil tebu terbesar ke 8 di dunia sebanyak 33,7 juta ton per tahun dan penghasil jagung terbesar ketujuh di dunia sebanyak 28 juta ton per tahun. Limbah dari kedua produk ini adalah bonggol jagung dan ampas tebu yang masih belum banyak dimanfaatkan ${ }^{5 \text { ) }}$. 
Corn Cob Ash (CCA), yang merupakan abu dari pembakaran bonggol jagung dan Bagasse Ash (BA) yang merupakan hasil dari pembakaran ampas tebu, merupakan material yang memiliki potensi pengganti parsial semen karena memiliki komposisi $\mathrm{SiO}_{2}$ dan $\mathrm{Al}_{2} \mathrm{O}_{3}$ yang tinggi ${ }^{6-8)}$. Penelitian ini bertujuan untuk menganalisis komposisi oksida apa saja yang terdapat pada CCA dan BA melalui karakterisasi X-Ray Fluorscence (XRF) dan bagaimana pengaruh penambahan kedua material tersebut terhadap Setting Time, dan kuat tekan pada pasta semen.

\section{METODE}

\subsection{Material}

Material yang digunakan adalah Semen Tipe I merk Tiga Roda. Komposisi Oksida material tersebut ditunjukkan pada Tabel 1. CCA dan BA diperoleh dengan cara pembakaran bonggol jagung dan ampas tebu pada temperatur $700^{\circ} \mathrm{C}$ untuk membakar material organik sehingga menyisakan abu. Hasil pembakaran dapat dilihat pada Gambar 1. Untuk mengetahui komposisi oksida kedua material tersebut dilakukan uji X-Ray Fluorscence pada CCA dan BA di Center of Advanced Science (CAS) Institut Teknologi Bandung. Air yang digunakan merupakan tap-water yang terdapat di Institut Teknologi dan Sains Bandung (ITSB).
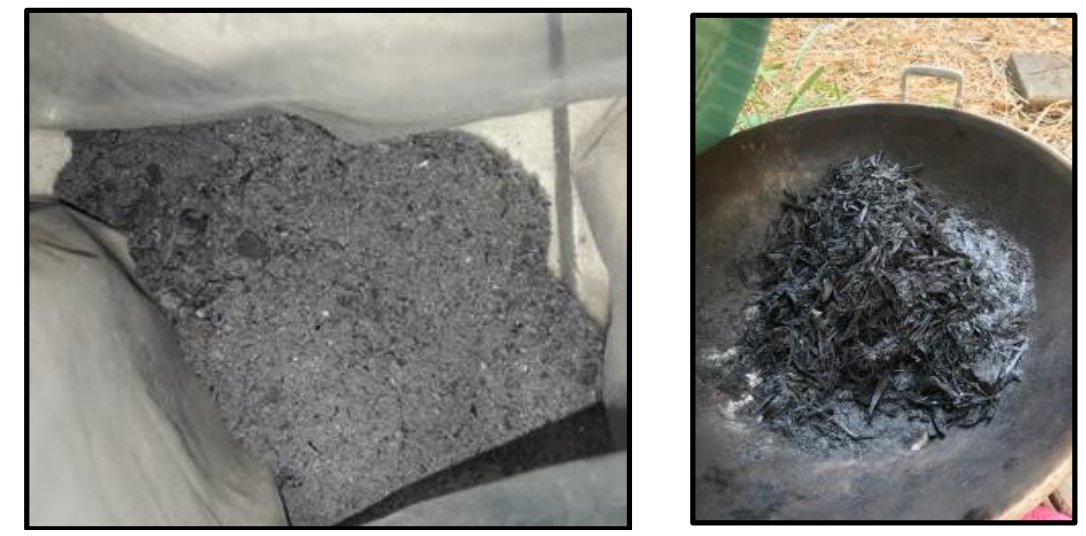

Gambar 1. Sisa pembakaran bonggol jagung (kiri) dan ampas tebu (kanan)

Tabel 1. Komposisi oksida semen

\begin{tabular}{cc}
\hline Senyawa & Konsentrasi $(\%)$ \\
\hline $\mathrm{SiO}_{2}$ & 19.3 \\
$\mathrm{Al}_{2} \mathrm{O}_{3}$ & 3.67 \\
$\mathrm{Fe}_{2} \mathrm{O}_{3}$ & 3.44 \\
$\mathrm{CaO}$ & 59.8 \\
$\mathrm{MgO}$ & 2.18 \\
$\mathrm{SO}_{3}$ & 3.34 \\
$\mathrm{Na}_{2} \mathrm{O}$ & 0.12 \\
$\mathrm{TiO}_{2}$ & 0.6 \\
$\mathrm{~K}_{2} \mathrm{O}$ & 0.22 \\
$\mathrm{P}_{2} \mathrm{O}_{5}$ & 0.08 \\
$\mathrm{MnO}$ & 0.24 \\
\hline
\end{tabular}




\subsection{Metode}

Mix Design penelitian dapat dilihat pada Tabel 2. Rasio air semen (w/c) yang digunakan adalah 0.6. Persentase CCA dan BA yang digunakan pada penelitian ini adalah $0 \%$ (kontrol), $25 \%$, dan $50 \%$.

Tabel 2. Mix design penelitian

\begin{tabular}{ccccc}
\hline No & Nama & Semen $(\%)$ & CCA $(\%)$ & BA $(\%)$ \\
\hline 1 & Control & 100 & 0 & 0 \\
2 & CCA-25 & 75 & 25 & 0 \\
3 & CCA-50 & 50 & 50 & 0 \\
4 & BA-25 & 75 & 0 & 25 \\
5 & BA-50 & 50 & 0 & 50 \\
\hline
\end{tabular}

Setelah pencampuran, dilakukan pengujian Setting Time dengan menggunakan alat Vicat Apparatus sesuai dengan ASTM C-191 seperti pada Gambar 2. Kemudian, sampel dicetak pada cetakan berukuran 50x50x50mm, dibiarkan selama 24 Jam, dibuka dari cetakan, kemudian disimpan menggunakan metode ambient curing dengan cara menutup sampel dengan kain basah. Sampel kemudian dilakukan pengujian tekan pada umur 3, 7, dan 28 hari di Center of Infrastructure Built Environmental (CIBE) Institut Teknologi Bandung.

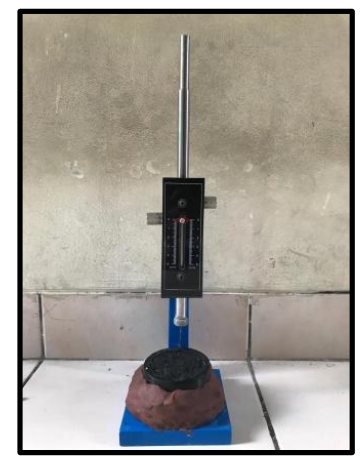

Gambar 2. Pengujian setting time menggukanan Vicat Apparatus.

\section{PEMBAHASAN DAN DISKUSI}

\subsection{Analisis XRF}

Analisis perbandingan antara semen, CCA, dan BA dapat dilihat pada Tabel 3. Dapat dilihat bahwa baik CCA maupun BA memiliki komposisi utama yang mirip dengan semen, yakni $\mathrm{CaO}, \mathrm{Al}_{2} \mathrm{O}_{3}$, dan $\mathrm{SiO}_{2}$, sehingga material ini cukup potensial untuk digunakan sebagai substitutor parsial dari semen. Oksida lain yang memiliki persentase yang cukup besar pada CCA dan BA adalah $\mathrm{K}_{2} \mathrm{O}$, sehingga penambahan CCA dan BA dapat meningkatkan alkalinitas dari material berbasis semen. $\mathrm{P}_{2} \mathrm{O}_{5}$ yang tinggi akan mengakibatkan kebutuhan air meningkat ${ }^{9)}$. Jumlah $\mathrm{Fe}_{2} \mathrm{O}_{3}$ yang tinggi dapat mempengaruhi setting time dari pasta. $\mathrm{SO}_{3}$ dapat mempengaruhi laju hidrasi dari semen ${ }^{10)}$. 
Tabel 3. Perbandingan komposisi oksida semen, CCA, dan BA

\begin{tabular}{cccc}
\hline \multirow{2}{*}{ Senyawa } & \multicolumn{3}{c}{ Konsentrasi $(\%)$} \\
\cline { 2 - 4 } & Semen & CCA & BA \\
\hline $\mathrm{SiO}_{2}$ & 19.3 & 23.38 & 58.48 \\
$\mathrm{Al}_{2} \mathrm{O}_{3}$ & 3.67 & 2.17 & 0.94 \\
$\mathrm{Fe}_{2} \mathrm{O}_{3}$ & 3.44 & 5.67 & 0.79 \\
$\mathrm{CaO}$ & 59.8 & 5.99 & 6.12 \\
$\mathrm{MgO}$ & 2.18 & 6.11 & 4.46 \\
$\mathrm{SO}_{3}$ & 3.34 & 2.87 & 6.90 \\
$\mathrm{Na}_{2} \mathrm{O}$ & 0.12 & - & - \\
$\mathrm{TiO}_{2}$ & 0.6 & 1.20 & - \\
$\mathrm{K}_{2} \mathrm{O}$ & 0.22 & 23.91 & 12.71 \\
$\mathrm{P}_{2} \mathrm{O}_{5}$ & 0.08 & 28.09 & 9.43 \\
$\mathrm{MnO}$ & 0.24 & 0.15 & 0.17 \\
\hline
\end{tabular}

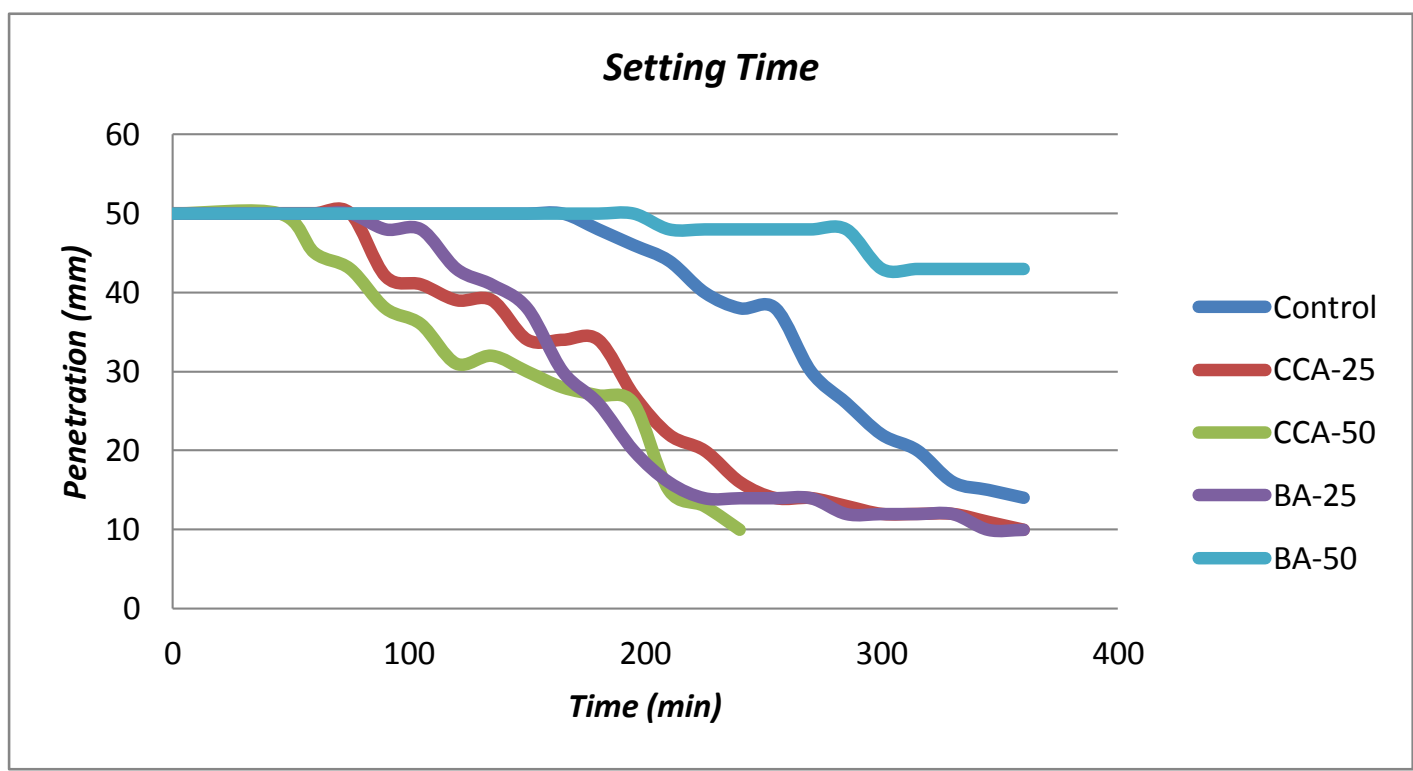

Gambar 3. Hasil pengujian Setting Time sampel Control, CCA-25, CCA-50, BA-25, dan BA-50.

\subsection{Analisis Setting Time}

Hasil pengujian Setting Time menggunakan Vicat Apparatus dapat dilihat pada Gambar 3. Sampel kontrol dapat dilihat bahwa Setting Time dari sampel CCA-50 dapat meningkatkan waktu setting dari sampel, sedangkan BA-50 memperlambat waktu setting dari sampel. Hal ini dapat dikaitkan dengan komposisi $\mathrm{Fe}_{2} \mathrm{O}_{3}$ dari masing-masing material, semen $3.44 \%$, CCA 5.67\%, dan BA 0.79\%. Semakin tinggi kadar $\mathrm{Fe}_{2} \mathrm{O}_{3}$ pada suatu material maka setting time nya akan semakin cepat dan sebaliknya $\mathrm{Fe}_{2} \mathrm{O}_{3}$ yang sedikit akan memperlambat setting time dari pasta. 


\subsection{Analisis Kuat Tekan}

Hasil kuat tekan dapat dilihat pada Gambar 4 yang dihitung dengan menggunakan rumus di bawah ini:

$$
\sigma=\frac{F}{A}
$$

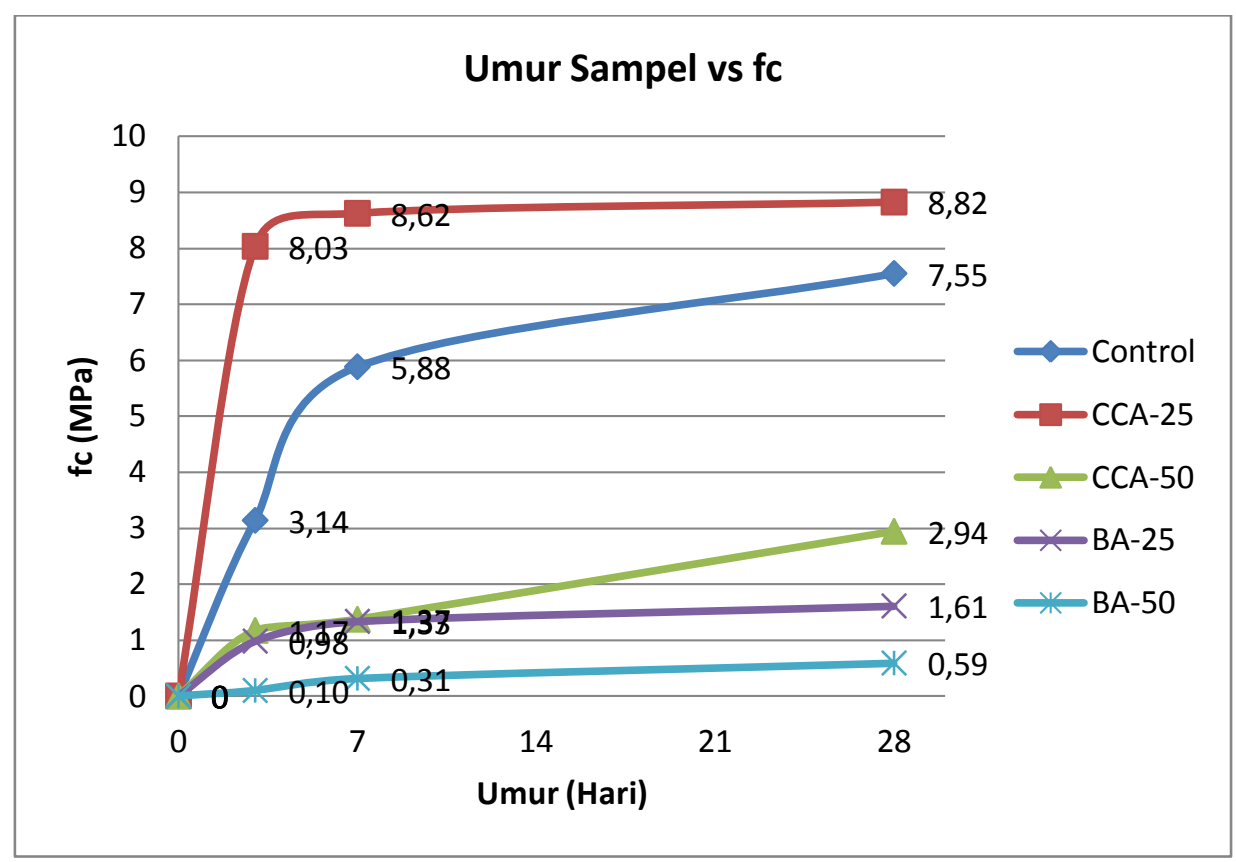

Gambar 4. Hasil kuat tekan pasta dengan penambahan CCA dan BA

Sampel CCA-25 memiliki kuat tekan umur 28 hari yang lebih tinggi dari sampel kontrol, sedangkan CCA-50, BA-25, dan BA-50 memiliki kuat tekan yang lebih rendah. $\mathrm{Hal}$ ini dapat disebabkan pada sampel dengan CCA-25 memberikan $\mathrm{SiO}_{2}, \mathrm{Al}_{2} \mathrm{O}_{3}$, dan $\mathrm{CaO}$ yang cukup untuk memperbaiki laju hidrasi pada semen kontrol, sedangkan pada sampel lain, kelebihan $\mathrm{K}_{2} \mathrm{O}, \mathrm{P}_{2} \mathrm{O}_{5}$, dan $\mathrm{SO}_{3}$ dapat membuat reaksi hidrasi tidak dapat berlangsung dengan sempurna dan terbentuk senyawa lain sehingga dapat menurunkan kuat tekan dari sampel pasta.

\section{KESIMPULAN}

Hasil pengujian Vicat Apparatus menunjukkan bahwa Setting Time campuran semen dengan CCA 25\% akan lebih cepat dari sampel kontrol, sedangkan penambahan BA 50\% akan memperlambat Setting Time dari pasta. Nilai kuat tekan semen dengan campuran 25\% CCA dan BA adalah masing-masing 8,82 MPa dan 1,61 MPa. Rekomendasi untuk penelitian selanjutnya adalah melakukan analisa $X$-Ray Diffraction (XRD) untuk melihat senyawa terbentuk, Scanning Electron Microscope (SEM) untuk melihat morfologi permukaan sampel, dan Energy Dispersive X-Ray Spectroscopy (EDS) untuk mengklarifikasi unsur pada gambar SEM sehingga senyawa yang terbentuk dapat 
ditentukan. Selain itu CCA dan BA dapat digunakan sebagai pengganti agregat halus untuk pembuatan mortar atau beton.

\section{UCAPAN TERIMA KASIH}

Penulis mengucapkan terima kasih kepada Laboratorium Center of Infrastructure Built Environmental (CIBE) dan Center of Advanced Science (CAS) Institut Teknologi Bandung atas bantuannya dalam pengujian Kuat Tekan dan XRF pada sampel uji pasta.

\section{DAFTAR PUSTAKA}

1) Barcelo, L., Kline, J., Walenta, G., Gartner, E.M. (2014). Cement and Carbon Emssions: Materials and Structures 47 (6).

2) Andrew, R.M. (2014). Global $\mathrm{CO}_{2}$ emissions from cement production: Earth Syst. Sci. Data, 10, 195-217.

3) El-gray, A.A., Ahmed, F.B.M. (2016). Determination of Major Oxides Percentages in Portland Cement of Some Sudanese Cement Manufactories: American Journal of Applied Chemistry, 4(1): 14-17.

4) Kucharczyk, S., Zajac, M., Deja, J. (2015). The influence of limestone and $\mathrm{Al}_{2} \mathrm{O}_{3}$ content in the slag on the performance of the composite cements: Procedia Engineering, 108, 402-409.

5) Anand, A., Mishra, A.K. (2016). Comparative study of concrete strength by partially replacing cement with sugarcane bagasse ash and Fly Ash: International Journal of Science, Engineering and Technology Research, 5(4).

6) Suwanmaneechot, P., Nochaiya, T., Julphunthong, P. (2015). Improvement, characterization and use of waste corn cob ash in cement-based materials: IOP Conf. Series: Materials Science and Engineering, 103.

7) Abdulkadir, T.S., Oyejobi, D.O., Lawal, A.A. (2014). Evaluation of sugarcane bagasse ash as a replacement for cement in concrete works: Acta Tehnica Corviniensis - Bulletin of Engineering Tome VII.

8) Yashwanth, M.K., Avinash, G.B., Raghavendra, A. Naresh, K.B.G. (2017). An experimental study on alternative cementitious materials: Bagasse ash as partial replacement for cement in structural lightweight concrete: The Indian Concrete Journal.

9) Nurse, R.W. (2007). The Effect of Phosphate on the Constitution and Hardening of Portland Cement: Journal of Applied Chemistry, 2(12): 708-716.

10) Horkoss, S., Escadeillas, G., Rizk, T., Lteif, R. (2016) The effect of the source of cement SO3 on the expansion of mortars: Case Studies in Construction Materials, 4: 62-72. 